\title{
Safety profile of prophylactic rescue dosing of immediate-release oral opioids in cancer patients
}

\author{
Rei Tanaka ${ }^{1 *}$ D, Hiroshi Ishikawa ${ }^{1}$, Tetsu Sato ${ }^{1}$, Michihiro Shino ${ }^{1}$, Katsuhiro Omae ${ }^{2}$, Tetsumi Sato ${ }^{3}$ and Iwao Osaka ${ }^{3}$
}

\begin{abstract}
Background: Appropriate prophylactic rescue dosing of opioids is considered effective for cancer pain relief, but no study has reported the safety of such prophylactic rescue. We compared the safety of prophylactic rescue dosing of immediate-release oral opioids with that of regular rescue dosing.

Methods: The study included 103 cancer patients who used either immediate-release morphine syrup or immediaterelease oxycodone powder at Shizuoka Cancer Center between January and December 2016. Patients were divided into those who mostly used (prophylactic group) and those who never used (regular group) prophylactic rescue doses of opioids and compared the incidence of adverse events (AEs). We also investigated whether the prophylactic rescue dose negatively interfered with its objective activity, such as meals.
\end{abstract}

Results: Incidence of each AE in the prophylactic versus regular groups was as follows: somnolence, $20.6 \%$ versus 14.3\%; nausea, $22.1 \%$ versus $17.1 \%$; constipation, $19.1 \%$ versus $20.0 \%$; urinary retention, $1.5 \%$ versus $2.9 \%$; delirium, $4.4 \%$ versus $8.6 \%$; and pruritus, $0 \%$ versus $2.9 \%$. No serious AE associated with prophylactic rescue dosing was observed. No significant difference was observed in the incidence of any AE between the two groups ( $p>0.05$, Fisher's exact test). No AE interfered with the objective activity of the prophylactic rescue dose.

Conclusion: Incidence of AEs associated with prophylactic rescue dosing is not different from that associated with regular rescue dosing. In addition, the prophylactic rescue dose did not adversely affect its objective activity, suggesting the safety of appropriate prophylactic rescue dosing was similar to that of regular rescue dosing.

Trial registration: The study approval number in the institution; H29-J30-29-1-3. Registered June 5, 2017.

Keywords: Opioid, Rescue dose, Immediate-release opioid, Prophylactic rescue, Morphine, Oxycodone

\section{Background}

Appropriate use of immediate-release opioid oral agents is a critical component of cancer pain relief. This is also supported by the principles of analgesics use specified in the WHO cancer pain relief program [1,2], which state that immediate-release agents should be administered orally at individualized doses with meticulous care.

Until recently, oral opioids were only available in an immediate-release form requiring multiple daily doses. The subsequent development of the extended-release oral formulations of morphine [3], oxycodone [4], and

\footnotetext{
*Correspondence: r.tanaka@scchr.jp

'Department of Pharmacy, Shizuoka Cancer Center, 1007 Shimonagakubo,

Nagaizumi-cho, Sunto-gun, Shizuoka-ken 411-8777, Japan

Full list of author information is available at the end of the article
}

tapentadol [5], and the fentanyl extended-release patch [6] has led to decreased daily regular dosing frequency of opioids. Improvements have also been made to immediate-release agents, such as the development of the buccal tablet [7] and sublingual tablet [8] formulations of fentanyl, which otherwise undergoes extensive first-pass metabolism. The combined use of a regular dose of an extended-release agent and a rescue dose of an immediate-release agent has become widely accepted as a standard of care. A comparison of the analgesic effect of extended-release and immediate-release agents has shown no significant difference in terms of efficacy and incidence of adverse events (AEs) [9]. It is nevertheless considered preferable to combine the two formulations for better patient adherence $[10,11]$. 
Immediate-release agents require some time before the blood concentration of orally administered opioid starts to increase $\left(\mathrm{T}_{\max }=0.9 \mathrm{~h}\right.$ for immediate-release morphine syrup [12] and $1.9 \mathrm{~h}$ for immediate-release oxycodone powder [13]). A previous study has also shown that the onset of action for the analgesic effect of an immediate-release opioid is $30 \mathrm{~min}$ to $1 \mathrm{~h}$, as assessed by a reduction on the Numeric Rating Scale (NRS) for pain [14]. Therefore, prophylactic rescue dosing is often used in clinical practice, especially before activities that may cause breakthrough pain, such as body movement, interventions, and meals [15]. Currently, the efficacy of prophylactic rescue dosing has not yet been reported. However, recommendations from the European Association for Palliative Care (EAPC) in 2012 advocated prophylactic use of immediate-release agents, more precisely, administration of such agents 20-30 min before the predicted episode of breakthrough pain [16], and guidelines of the Japanese Society for Palliative Medicine (JSPM), published in 2014, recommended oral administration of an immediate-release opioid 30-60 min before the predicted episode of breakthrough pain when triggers are not eliminated [17]. Moreover, no study has reported the safety of prophylactic rescue dosing. Anticipated problems associated with prophylactic rescue dosing include AEs such as somnolence and nausea, which may interfere with prophylactic interventions, and increased total opioid dose, which may result in increased incidence of dose-dependent AEs, such as constipation and delirium $[18,19]$. In this study, we compared the incidence of AEs associated with prophylactic versus regular rescue dosing of two easy-to-use, widely available opioids, namely, immediate-release morphine syrup and the immediate-release oxycodone powder.

\section{Methods}

This study included 103 cancer patients hospitalized at Shizuoka Cancer Center who had started using the immediate-release morphine syrup or immediate-release oxycodone powder between January and December 2016. The study period was defined as the time from the start to discontinuation or change of treatment. Patients were divided into those who used (prophylactic group) and did not use (regular group) a prophylactic rescue dose of opioid. In this study, based on the EAPC recommendations [16] and the JSPM guidelines [17], we defined prophylactic rescue dose as a rescue dose within $1 \mathrm{~h}$ before an activity expected to cause breakthrough pain, such as meals, bedtime, radiation therapy, rehabilitation or intervention. The prophylactic group contained patients for whom more than half of all rescue doses were prophylactic, and the regular group contained patients for whom no rescue doses were prophylactic. The objective activities of prophylactic rescue doses were also examined in the prophylactic group.

Electronic medical records were retrospectively reviewed to extract six opioid-related AEs (somnolence, nausea, constipation, urinary retention, delirium, and pruritus) selected from those listed in the JSPM guidelines [17] based on our clinical importance, and the incidence of each $\mathrm{AE}$ was compared between groups. We also analyzed the incidence of serious AEs, including fall, loss of consciousness, and respiratory depression and determined which serious AE interfered with the objective activity of the prophylactic rescue dose. AEs of grade 2 or higher, according to the Common Terminology Criteria for Adverse Events (CTCAE) Ver. 4.0, were included in the analysis. Fisher's exact test was used for statistical analysis of the AEs, with a significance level of 0.05. We also investigated whether patients used preventive medicines for AEs of prophylactic rescue, such as antiemetic drugs. Patients who had undergone chemotherapy during the study period were excluded because of the considerable influence of chemotherapy on the occurrence of AEs such as somnolence and nausea.

The two groups were compared for the following patient background factors that could potentially affect the incidence of AEs: amount of each single rescue dose, daily total rescue dose, dosing duration, dosing frequency, distribution and dose of concomitant extended-release opioids, age, sex, performance status, distribution of carcinoma (head and neck cancer, lung cancer, breast cancer, digestive system cancer, urological cancer, gynecological cancer, skin cancer, and others), renal dysfunction, and hepatic dysfunction. According to the CTCAE ver. 4.0, a grade 1 or higher elevation in serum creatinine level $(\geq 1.04$ and $\geq 0.79 \mathrm{mg} / \mathrm{dL}$ in men and women, respectively) was defined as renal dysfunction, and a grade 1 or higher elevation in serum aspartate aminotransferase/alanine transaminase level $(\geq 40 \mathrm{U} / \mathrm{L}$ for both) was defined as hepatic dysfunction. For statistical analysis, the Mann-Whitney U test was used for the comparison of the amount of each single rescue dose, daily total rescue dose, dosing duration, dosing frequency, dose of concomitant extended-release opioids, and age. The Cochran-Armitage trend test was used for distribution of extended-release opioids and distribution of carcinoma, and Fisher's exact test was used for the remaining factors, with a significance level of 0.05 .

This study was conducted in compliance with the Ethical Guidelines for Medical Research in Humans, and with approval by the ethics committee at Shizuoka Cancer Center. The first author (R.T.) conducted all retrospective reviews of electronic medical records filled in by doctors, nurses, or pharmacists (including the first author) and statistical analyses. 


\section{Results}

Of the 103 patients included in the study, 68 and 35 patients were in the prophylactic and regular groups, respectively. Patients were further divided into subgroups based on the type of opioid used; 38, 30, 14, and 21 patients were in the prophylactic morphine, prophylactic oxycodone, regular morphine, and regular oxycodone groups, respectively (Fig. 1).

Concomitant extended-release opioids included 12-h extended-release oral morphine, 12-h extended-release oral oxycodone, 12-h extended-release oral tapentadol, and 1-day extended-release fentanyl patch. As shown in Table 1, the distribution of morphine was relatively high in the prophylactic group (55.9 and $39.8 \%$ in patients who received immediate-release and extended-release opioids, respectively), while that of oxycodone was relatively high in the regular group 60.0 and $54.2 \%$ in those who received immediate-release and extended-release opioids, respectively), although there were no significant differences between the two groups $(\mathrm{P} \geq 0.05)$. Of all patients, $17.5 \%$ (prophylactic group: 19.1\%; regular group: $14.3 \%$ ) used no 12-h extended-release opioid and used only rescue-dose immediate-release opioids.

No significant difference was observed between the prophylactic and regular groups for any of the patient background factors. The conversion ratios of each opioid agent were as follows: oral morphine/oral oxycodone/ oral tapentadol/fentanyl patch $=30: 20: 100: 1$ [20-22].

We also investigated the purpose for which prophylactic rescue doses were used. We found that patients used a prophylactic rescue dose before meals (pain relief while eating), before bedtime (pain relief while falling asleep), before meals and bedtime (pain relief while eating and falling asleep), before radiation therapy (pain relief during radiation therapy) or before rehabilitation/intervention (pain relief during rehabilitation or intervention), and that patients decided to use a prophylactic rescue dose on their own for relief of pain, respiratory distress, or abdominal bloating. The distribution of the purposes of use is shown in Table 2.

The incidence of each $\mathrm{AE}$ in the prophylactic versus regular groups was as follows: somnolence, $20.6 \%$ versus $14.3 \%$; nausea, $22.1 \%$ versus $17.1 \%$; constipation, $19.1 \%$ versus $20.0 \%$; urinary retention, $1.5 \%$ versus $2.9 \%$; delirium, $4.4 \%$ versus $8.6 \%$; and pruritus, $0 \%$ versus $2.9 \%$. Thus, no significant difference was observed in the incidence of any AE between the two groups (Table 3). Furthermore, there were no serious AEs attributable to the prophylactic rescue dose, such as fall, loss of consciousness, respiratory depression or interfering with the objective activity of the prophylactic rescue dose. None of the patients discontinued the use of opioid due to an effect of prophylactic rescue dosing. None of the patients in this study had drug dependence, such as chemical coping, or used preventive medicines for AEs of prophylactic rescue.

Tables 4 and 5 show the results of subgroup analysis based on opioid type in the morphine and oxycodone subgroups, respectively. In both subgroups, no significant difference in $\mathrm{AE}$ incidence was observed between the prophylactic and regular groups.

\section{Discussion}

This study showed no significant difference between the prophylactic and regular rescue dose groups in the incidence of any of the AEs evaluated, including somnolence, nausea, constipation, urinary retention, delirium, and

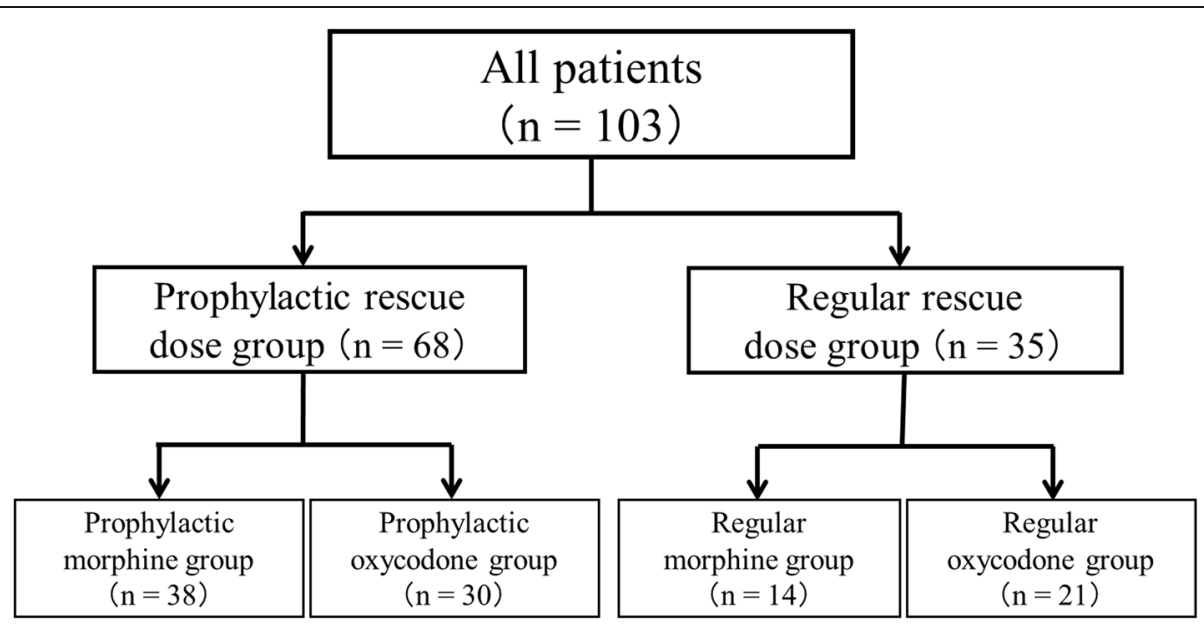

Fig. 1 The device for quantitative analyses of perception and painful sensations and its probe. Fig. 1 indicated the 103 patients included in the study, 68 and 35 patients were in the prophylactic and regular groups, respectively. Patients were further divided into subgroups based on the type of opioid used; 38, 30, 14, and 21 patients were in the prophylactic morphine, prophylactic oxycodone, regular morphine, and regular oxycodone groups, respectively 
Table 1 Patient background

\begin{tabular}{|c|c|c|c|}
\hline \multirow[t]{2}{*}{ Patient background factor } & Prophylactic rescue & Regular rescue & \multirow[t]{2}{*}{$P$ value } \\
\hline & $n=68$ & $n=35$ & \\
\hline \multicolumn{4}{|l|}{ Distribution of immediate-release opioids, n (\%) } \\
\hline Morphine syrup & $38(55.9)$ & $14(40.0)$ & \multirow[t]{2}{*}{$0.15^{\mathrm{a}}$} \\
\hline Oxycodone powder & $30(44.1)$ & $21(60.0)$ & \\
\hline \multicolumn{4}{|l|}{ Median single rescue dose $(\mathrm{mg})^{d}$} \\
\hline All patients & $5(3.75-15)$ & $3.75(3.75-15)$ & $0.63^{b}$ \\
\hline Morphine syrup & $5(5-15)$ & $5(5-15)$ & $0.38^{b}$ \\
\hline Oxycodone powder & $3.75(3.75-15)$ & $3.75(3.75-15)$ & $0.32^{b}$ \\
\hline \multicolumn{4}{|l|}{ Median total rescue dose $(\mathrm{mg} / \text { day })^{\mathrm{d}}$} \\
\hline All patients & $15(0-45)$ & $10(0-40)$ & $0.21^{b}$ \\
\hline Morphine syrup & $15(0-40)$ & $10(0-40)$ & $0.32^{b}$ \\
\hline Oxycodone powder & $7.5(0-45)$ & $7.5(0-30)$ & $0.36^{\mathrm{b}}$ \\
\hline Distribution of extended-release opioids, $n$ (\%) & & & $0.17^{c}$ \\
\hline 12-h extended-release oral morphine & $27(39.8)$ & $8(22.9)$ & \\
\hline 12-h extended-release oral oxycodone & $24(35.2)$ & $19(54.2)$ & \\
\hline 12-h extended-release oral tapentadol & $3(4.4)$ & $1(2.9)$ & \\
\hline 1-day extended-release fentanyl patch & $1(1.5)$ & $2(5.7)$ & \\
\hline None & $13(19.1)$ & $5(14.3)$ & \\
\hline Median regular dose of extended-release opioid (mg/day) ${ }^{d}$ & $15(0-75)$ & $15(0-90)$ & $0.52^{\mathrm{b}}$ \\
\hline Median duration of rescue dose (day) & $21(7-178)$ & $17(7-142)$ & $0.51^{\mathrm{b}}$ \\
\hline Median frequency of rescue dose (times/day) & $3(0-8)$ & $2(0-8)$ & $0.30^{\mathrm{b}}$ \\
\hline Median age (range) & 69 (37-94) & $69(21-86)$ & $0.19^{b}$ \\
\hline \multicolumn{4}{|l|}{ Sex, $n(\%)$} \\
\hline Men & $45(23)$ & $22(70.3)$ & \multirow[t]{2}{*}{$0.64^{\mathrm{a}}$} \\
\hline Women & $14(35.0)$ & $13(29.7)$ & \\
\hline \multicolumn{4}{|l|}{ Performance status, $n$ (\%) } \\
\hline$\leq 2$ & $46(45.0)$ & $21(51.2)$ & \multirow[t]{2}{*}{$0.66^{\mathrm{a}}$} \\
\hline$\geq 3$ & $22(55.0)$ & $20(48.8)$ & \\
\hline Distribution of carcinoma, $n$ (\%) & & & $0.43^{c}$ \\
\hline Head and neck cancer & $17(25.0)$ & $9(25.7)$ & \\
\hline Lung cancer & $18(26.5)$ & $7(20.0)$ & \\
\hline Breast cancer & $3(4.4)$ & $2(5.7)$ & \\
\hline Digestive system cancer & $15(22.1)$ & $10(28.6)$ & \\
\hline Urological cancer & $5(7.4)$ & $1(2.9)$ & \\
\hline Gynecological cancer & $3(4.4)$ & $3(8.6)$ & \\
\hline Skin cancer & $2(2.9)$ & $1(2.9)$ & \\
\hline Others & $5(7.4)$ & $2(5.7)$ & \\
\hline Renal dysfunction, $n$ (\%) & $11(25.0)$ & $5(36.7)$ & $0.34^{\mathrm{a}}$ \\
\hline Hepatic dysfunction, $n$ (\%) & $13(27.5)$ & $6(36.7)$ & $0.48^{\mathrm{a}}$ \\
\hline
\end{tabular}

a) Fisher's exact test

b) Mann-Whitney U test

c) Cochran-Armitage trend test

d) Converted to oral morphine equivalent doses

(oral morphine/oral oxycodone/oral tapentadol/fentanyl patch $=30: 20: 100: 1$ ) 
Table 2 Purposes of use of prophylactic rescue doses

\begin{tabular}{|c|c|c|c|}
\hline Purpose & $\begin{array}{l}\text { Prophylactic morphine } \\
n=38\end{array}$ & $\begin{array}{l}\text { Prophylactic oxycodone } \\
n=30\end{array}$ & $\begin{array}{l}\text { Total } \\
n=68\end{array}$ \\
\hline Before meals (pain relief while eating) & 13 & 3 & 16 \\
\hline Before bedtime (pain relief while falling asleep) & 3 & 10 & 13 \\
\hline Before meals and bedtime (pain relief while eating and falling asleep) & 6 & 2 & 8 \\
\hline Before radiation therapy (pain relief during radiation therapy) & 6 & 4 & 10 \\
\hline Before rehabilitation or intervention (pain relief during rehabilitation or intervention) & 2 & 6 & 8 \\
\hline Patient's decision to use for pain & 3 & 5 & 8 \\
\hline Patient's decision to use for respiratory distress & 4 & 0 & 4 \\
\hline Patient's decision to use for abdominal bloating & 1 & 0 & 1 \\
\hline
\end{tabular}

pruritus (Table 3), suggesting that the use of prophylactic rescue dosing and associated increase in total opioid dose do not increase the incidence of AEs. Moreover, with no reported cessation of eating due to nausea, cessation of rehabilitation, intervention or radiation therapy due to somnolence, or refusal of prophylactic rescue dose by patients, it is likely that appropriate prophylactic rescue dosing also improves patients' QOL. The results of subgroup analysis also suggest the safety of prophylactic rescue dosing regardless of whether morphine syrup or oxycodone powder is used (Tables 4 and 5).

However, comparison of $\mathrm{AE}$ incidence between the morphine and oxycodone subgroups showed a lower incidence of constipation in patients using rescue-dose oxycodone, especially in those using prophylactic rescuedose oxycodone, compared with that in those using rescue-dose morphine. This difference may be explained by the differences in the amount of each rescue single dose and daily total dose between the two subgroups (Table 1). The minimum standard strength of the immediate-release morphine syrup and the immediate-release oxycodone powder in Japan is $5 \mathrm{mg}$ morphine and $2.5 \mathrm{mg}$ oxycodone (3.75 $\mathrm{mg}$ morphine equivalence), respectively. The morphine subgroup was associated with a higher frequency of prophylactic rescue doses

Table 3 Comparison of the incidence of adverse events between the prophylactic and regular groups in the entire study population

\begin{tabular}{llll}
\hline Adverse event & $\begin{array}{l}\text { Prophylactic rescue } \\
n=68\end{array}$ & $\begin{array}{l}\text { Regular rescue } \\
n=35\end{array}$ & $\begin{array}{l}P \text { value } \\
\text { Somnolence, } n(\%)\end{array}$ \\
Nausea, $n(\%)$ & $15(22.1)$ & $5(14.3)$ & $0.59^{\mathrm{a}}$ \\
Constipation, $n(\%)$ & $13(19.1)$ & $7(17.1)$ & $0.62^{\mathrm{a}}$ \\
Urinary retention, $n(\%)$ & $1(1.5)$ & $1(20.0)$ & $1.00^{\mathrm{a}}$ \\
Delirium, $n(\%)$ & $3(4.4)$ & $3(8.6)$ & $1.00^{\mathrm{a}}$ \\
Pruritus, $n(\%)$ & $0(0)$ & $1(2.9)$ & $0.40^{\mathrm{a}}$ \\
\hline
\end{tabular}

${ }^{a}$ Fisher's exact test before meals, with many of these patients having at least 3 doses per day; this might have also contributed to the difference. Another possible explanation is that the patients included in this study were administered relative low doses of extended-release opioids, with a median morphine equivalent dose of $15 \mathrm{mg} /$ day, along with the pharmacological difference that the threshold concentration for causing constipation is lower with morphine than oxycodone [23].

Regarding the purpose of use, patients used prophylactic rescue dosing most commonly before meals in the morphine subgroup and before bedtime in the oxycodone subgroup (Table 2). This may be because many of the patients requiring prophylactic rescue dose before meals experienced pain during swallowing due to underlying disease or prior radiation therapy of the esophagus, and therefore selected the syrup formulation rather than powder, because they are easier to swallow. In contrast, those requiring prophylactic rescue dose before bedtime tended to be concerned about pain during nighttime resting or while falling asleep, and therefore selected oxycodone for the longer-lasting analgesic effect because the half-life is longer than that of morphine [24] $\left(\mathrm{T}_{1 / 2}=2.2 \mathrm{~h}\right.$ for the immediate-release morphine syrup [12] and $6.0 \mathrm{~h}$ for the

Table 4 Comparison of the incidence of adverse events between the prophylactic and regular groups in the morphine subgroup

\begin{tabular}{llll}
\hline Adverse event & $\begin{array}{l}\text { Prophylactic } \\
\text { morphine } \\
n=38\end{array}$ & $\begin{array}{l}\text { Regular } \\
\text { morphine } \\
n=14\end{array}$ & $P$ value \\
\hline Somnolence, $n(\%)$ & $6(15.8)$ & $2(14.3)$ & $1.00^{a}$ \\
Nausea, $n(\%)$ & $10(26.3)$ & $4(28.6)$ & $1.00^{\mathrm{a}}$ \\
Constipation, $n(\%)$ & $12(31.6)$ & $4(28.6)$ & $1.00^{\mathrm{a}}$ \\
Urinary retention, $n(\%)$ & $0(0)$ & $1(7.1)$ & $0.27^{\mathrm{a}}$ \\
Delirium, $n(\%)$ & $2(5.3)$ & $1(7.1)$ & $1.00^{\mathrm{a}}$ \\
Pruritus, $n(\%)$ & $0(0)$ & $1(7.1)$ & $0.27^{\mathrm{a}}$ \\
\hline
\end{tabular}

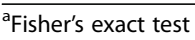


Table 5 Comparison of the incidence of adverse events between the prophylactic and regular groups in the oxycodone subgroup

\begin{tabular}{llll}
\hline Adverse event & $\begin{array}{l}\text { Prophylactic } \\
\text { oxycodone } \\
n=30\end{array}$ & $\begin{array}{l}\text { Regular } \\
\text { oxycodone } \\
n=21\end{array}$ & $P$ value \\
\hline Somnolence, $n$ (\%) & $8(26.7)$ & $3(14.3)$ & $0.49^{\mathrm{a}}$ \\
Nausea, $n(\%)$ & $5(16.7)$ & $2(9.5)$ & $0.69^{\mathrm{a}}$ \\
Constipation, $n(\%)$ & $1(3.3)$ & $3(14.3)$ & $0.29^{\mathrm{a}}$ \\
Urinary retention, $n(\%)$ & $1(3.3)$ & $0(0)$ & $1.00^{\mathrm{a}}$ \\
Delirium, $n(\%)$ & $1(3.3)$ & $2(9.5)$ & $0.56^{\mathrm{a}}$ \\
Pruritus, $n(\%)$ & $0(0)$ & $0(0)$ & $1.00^{\mathrm{a}}$ \\
\hline
\end{tabular}

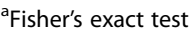

immediate-release oxycodone powder [13]). The higher frequency of use of prophylactic rescue for respiratory distress in the morphine subgroup was probably because evidence for efficacy in the relief of respiratory distress is widely available for morphine [25].

Future prospective studies using a predetermined rescue dose, a dosing frequency, a purpose, a dosing schedule, and a concomitant extended-release agent are needed to accumulate more detailed evidence. Also, we plan to compare other AEs which were unaddressed in the present study and to investigate the efficacy of prophylactic rescue dosing (e.g., by examining decreases in NRS pain assessment results).

Regarding concomitant extended-release opioids, due to the retrospective nature of the study, the presence of patients who used extended-release opioids containing types of opioids different from the immediate-release opioids and those who used no extended-release opioids, might have served as a confounding factor that affected the incidence of AEs. However, given that no serious AE, such as fall, loss of consciousness, respiratory depression, or drug dependence, was observed in the prophylactic group and that no increase in the incidence of somnolence or other AEs was observed in the analysis of the entire population, it is unlikely that serious problems could occur from using a prophylactic rescue dose of an immediate-release opioid with a concomitant extendedrelease agent containing a different type of opioid or without any concomitant extended-release agent.

\section{Conclusion}

The present results suggest that the incidence of AEs associated with prophylactic rescue dosing is not different from that associated with regular rescue dosing. Moreover, no AE interfered with the objective activity for which the prophylactic rescue dose was used, suggesting the safety of appropriate prophylactic rescue dosing was similar to that of regular rescue dosing.

\section{Abbreviations}

AE: adverse event; CTCAE: Common Terminology Criteria for Adverse Events: EAPC: European Association for Palliative Care; JSPM: Japanese Society for Palliative Medicine; NRS: Numeric Rating Scale

\section{Availability of data and materials}

The dataset supporting the conclusions of this article is included within the article.

\section{Authors' contributions}

RT designed this original concept, collected the data, and wrote the manuscript. HI, JS, and MS contributed to the discussion on pharmacology. $\mathrm{KO}$ helped with statistical analyses. TS and $\mathrm{IO}$ contributed to the discussion on palliative care.

\section{Authors' information}

RT, RPh. Ph.D.: Pharmacist at Shizuoka Cancer Center; HI, RPh.: Pharmacist at Shizuoka Cancer Center; TS, RPh.: Pharmacist at Shizuoka Cancer Center; MS, RPh.: Pharmacist at Shizuoka Cancer Center; KO.: Statistician at Shizuoka Cancer Center; TS, M.D. Ph.D.: Doctor at Shizuoka Cancer Center; IO, M.D.: Doctor at Shizuoka Cancer Center.

Ethics approval and consent to participate

This study was conducted with the approval of Shizuoka Cancer Center Ethical Review Board (approval number: H29-J30-29-1-3). https://www.scchr.jp/ clinicaltrial/wp-content/uploads/sites/13/2016/11/keizi29-6-13.pdf

\section{Consent for publication}

Not applicable.

\section{Competing interests}

All of authors declare that they have no competing interests.

\section{Publisher's Note}

Springer Nature remains neutral with regard to jurisdictional claims in published maps and institutional affiliations.

\section{Author details}

${ }^{1}$ Department of Pharmacy, Shizuoka Cancer Center, 1007 Shimonagakubo, Nagaizumi-cho, Sunto-gun, Shizuoka-ken 411-8777, Japan. ${ }^{2}$ Clinical Research Promotion Unit of Clinical Research Center, Shizuoka Cancer Center, 1007 Shimonagakubo, Nagaizumi-cho, Sunto-gun, Shizuoka-ken 411-8777, Japan. ${ }^{3}$ Department of Palliative Medicine, Shizuoka Cancer Center, 1007

Shimonagakubo, Nagaizumi-cho, Sunto-gun, Shizuoka-ken 411-8777, Japan.

Received: 30 January 2018 Accepted: 26 July 2018

Published online: 10 September 2018

\section{References}

1. World Health Organization. WHO Cancer Pain Relief. 1st ed. Geneva, Switzerland: World Health Organization; 1986.

2. World Health Organization. WHO Cancer Pain Relief: With a Guide to Opioid Availability. Geneva, Switzerland: World Health Organization; 1996.

3. Mercadante S. Opioid titration in cancer pain: a clinical review. Eur J Pain. 2007;11:823-30.

4. Poyhia R, Vainio A, Kalso E. A review of oxycodone's clinical pharmacokinetics and pharmacodynamics. J Pain Symptom Manag. 1993;8:63-7.

5. Afilalo M, Etropolski MS, Kuperwasser B, Kelly K, Okamoto A, Van HI, et al. Efficacy and safety of tapentadol extended release compared with oxycodone-controlled release for the management of moderate to severe chronic pain related to osteoarthritis of the knee: a randomized doubleblind, placebo- and active-controlled phase 3 study. Clin Drug Investig. 2010:30:489-505.

6. Canada H. Fentanyl transdermal patch and fatal adverse reactions. Can Adverse Reac Newslet. 2008;18(3):1-2

7. Weinstein SM, Messina J, Xie F. Fentanyl buccal tablet for the treatment of breakthrough pain in opioid-tolerant patients with chronic neuropathic pain. A long-term, open-label safety study. Cancer. 2009;115:2571-9.

8. Rauck RL, Tark M, Reyes E, Hayes TG, Bartkowiak AJ, Hassman D, et al. Efficacy and long-term tolerability of sublingual fentanyl orally 
disintegrating tablet in treatment of breakthrough cancer pain. Curr Med Res Opin. 2009;25:2877-85.

9. Kleptstad P, Kaasa S, Borchgrevink PC. Starting step 3 opioids for moderate to severe pain in cancer patients: dose titration: a systematic review. Palliat Med. 2011;25:424-30.

10. Davis MP, Walsh D, Lagman R, Legrand SB. Controversies in pharmacotherapy of pain management. Lancet Oncol. 2005;6:696-704.

11. Davis MP. Guidelines for breakthrough pain dosing. Am J Hosp Palliat Care. 2003;20:334.

12. Opso comprehensive drug information sheet. Tokyo: Dainihon Sumitomo Co., Ltd; 2014.

13. Oxinorm ${ }^{\oplus}$ comprehensive drug information sheet. Tokyo: Shionogi $\mathrm{Co}_{\text {., }}$ Ltd; 2014.

14. Couzzi PH, Schwartzberg L, Conroy JD, Charapata S, Gay M, Busch MA, et al. Breakthrough cancer pain: a randomized trial comparing oral transmucosal fentanyl citrate (OTFC) and morphine sulfate immediate release (MSR). Pain. 2001;91:123-30.

15. Magnani C, Giannarelli D, Casale G. Procedural pain in palliative care: is it breakthrough pain? A multicenter National Prospective Study to assess prevalence, intensity, and treatment of procedure-related pain in patients with advanced disease. Clin J Pain. 2017;33:707-14.

16. Augusto C, Geoffrey H, Stein K, Bannett Ml, Brunelli C, Chemy N, et al. Use of opioid analgesics in the treatment of cancer pain: evidence-based recommendations from the EAPC. Lancet Oncol. 2012;13:e58-68.

17. Japanese society for palliative medicine. Clinical guidelines for cancer pain management. 2nd ed. Tokyo: Kanehara Co.; 2014.

18. Gagnon B, Bilelech M, Watanabe S, Walker P, Hanson J, Bruera E. The use of intermittent subcutaneous injections of oxycodone for opioid rotation in patients with cancer pain. Support Care Cancer. 1999;7:265-70.

19. Mercadante S, Bruera E. Opioid switching: a systematic and critical review. Cancer Treat Rev. 2006;32:304-15.

20. National Comprehensive Cancer Network (Version 2): NCCN Clinical Practice Guidelines in Oncology. Adult cancer pain; 2016. https:// oralcancerfoundation.org/wp-content/uploads/2016/09/pain.pdf.

21. Hanks GW, de Conno F, Cherny N, Hanna M, Kalso E, Mcquay HJ, et al. Morphine and alternative opioids in cancer pain: the EAPC recommendations. Br J Cancer. 2001:84:587-93.

22. Fine PG, Portenoy RK. Establishing "best practices" for opioid rotation: conclusions of an expert panel. J Pain Symptom Manag. 2009:38:418-25.

23. Nakamura A, Hasegawa M, Ito H, Minami K, Koike K, Habu N, et al. Distinct relations among plasma concentration required for different pharmacological effects in oxycodone, morphine, and fentanyl. J Pain Palliat Care Pharmacother. 2011;4:318-34.

24. Lugo RA, Kern SE. The pharmacokinetics of oxycodone. J Pain Palliat Care Pharmacother. 2004;18:17-30.

25. Mazzocate C, Buclin T, Rapin CH. The effects of morphine on dyspnea and ventilator function in elderly patients with advanced cancer: a randomized double-blind controlled trial. Ann Oncol. 1999;10:1511-4.

Ready to submit your research? Choose BMC and benefit from:

- fast, convenient online submission

- thorough peer review by experienced researchers in your field

- rapid publication on acceptance

- support for research data, including large and complex data types

- gold Open Access which fosters wider collaboration and increased citations

- maximum visibility for your research: over $100 \mathrm{M}$ website views per year

At $\mathrm{BMC}$, research is always in progress.

Learn more biomedcentral.com/submissions 